\title{
Immigrant Status and Its Impact on Access to Health Care
}

\author{
Ignacio Navarro1,2, Juan Ibarra3 ${ }^{3}$ Andrew Anglemyer ${ }^{4}$ \\ ${ }^{1}$ Department of Health and Human Services \& Public Policy, California State University, Monterey Bay, Seaside, CA, USA \\ ${ }^{2}$ Institute for Community Collaborative Studies, California State University, Monterey Bay, Seaside, CA, USA \\ ${ }^{3}$ San Francisco Health Network, San Francisco, CA, USA \\ ${ }^{4}$ Operations Research Department, Naval Postgraduate School, Monterey, CA, USA \\ Email: ina varro@csumb.edu
}

How to cite this paper: Navarro, I., Ibarra, J. and Anglemyer, A. (2017) Immigrant Status and Its Impact on Access to Health Care. Open Journal of Social Sciences, 5, 85-97.

https://doi.org/10.4236/jss.2017.512007

Received: November 12, 2017

Accepted: December 11, 2017

Published: December 14, 2017

Copyright $\odot 2017$ by authors and Scientific Research Publishing Inc. This work is licensed under the Creative Commons Attribution-NonCommercial International License (CC BY-NC 4.0).

http://creativecommons.org/licenses/by-nc/4.0/

\begin{abstract}
This paper explores disparities in health care access for undocumented immigrants in the United States. Using the case of California, we find that less than half of undocumented immigrants in this state report having health insurance. Additionally, our estimates show that, among the insured, US-born and naturalized citizens are significantly more likely to have a doctor visit in the previous year when compared to undocumented immigrants (aOR $=1.53 \%$; $95 \%$ CI 1.15 - 2.04, aOR $=1.40 \%$; 95\% CI 1.05 - 1.87, respectively). Further, we find that US-born citizens are significantly more likely to use the ER in the previous year than undocumented immigrants, independent of insurance status. Our findings suggest that undocumented immigrants not only face barriers to obtain health insurance, but even with health insurance they face barriers to access health care services.
\end{abstract}

\section{Keywords}

Undocumented Immigrants, Health Services Accessibility, Patient Protection and Affordable Care Act, Insurance Coverage, Health Disparities

\section{Introduction}

Recent political developments in the United States (US) have brought both immigration and health reform to the front of current policy discussions at the national level. These discussions have touched on the role of the Affordable Care Act (ACA) in providing health care coverage for the most vulnerable populations and on the role of immigrants and especially undocumented immigrants filling a portion of the demand for minimum wage jobs in the US. One important aspect 
these policy debates have not fully addressed is the intersection of these two policy topics: specifically, the precarious conditions related to access to health care faced by undocumented immigrants in the US. This paper aims to fill this void by exploring the case of access to health care by undocumented immigrants in California. Using the California Health Interview Survey (CHIS), we explore disparities in health care access, coverage, and utilization by immigration status.

\section{Literature Review: Undocumented Immigrants and Access to Health Care}

The expansion of health insurance coverage under the ACA, specifically excludes undocumented immigrants [1]. As the ACA is implemented, however, its impact on access to health care for undocumented immigrants in California is still unclear. While undocumented immigrants are specifically excluded from the expansion of Medicaid and subsidies in health care exchange programs [1], provisions on the type of insurance coverage employers are required to offer may have a direct impact on this population.

The extent that health care access inequities have on the health of undocumented immigrants is multifaceted. Research suggests that the cumulative effects of undocumented immigrants being systematically excluded from health insurance (i.e., Medicaid, ACA, Emergency Medicaid depending on the state) combined with low household incomes, population increase for undocumented immigrants, chronic conditions, decreasing health levels with increasing time in the US, and the adoption of unhealthier behaviors all translate into worsening health inequities for this population [2] [3]. Concurrently, the health care expenditures for undocumented immigrants are much less than other citizens. Namely, recent research suggests that undocumented immigrants have the lowest health care expenditures across all types of health care settings (i.e., physician's office, outpatient, inpatient, emergency department, etc.) compared to legal residents, naturalized citizens, and U.S. born [4]. In fact, undocumented immigrants account for $\$ 15.4$ billion of the $\$ 96.5$ billion spent on annual health care spending among undocumented, legal, and naturalized immigrants [4]. In contrast, there was more than $\$ 1$ trillion spent on U.S. born citizens. Similarly, less than $8 \%$ of undocumented immigrants receive public sector health care benefits (approximately $\$ 140$ per person annually), while more than $30 \%$ of US born receive public sector health care benefits (approximately $\$ 1385$ per person annually) [4].

However, there are several operational and technical barriers for estimating health care needs of undocumented immigrants. The very nature of undocumented immigration poses challenges for accurate and reliable methods of its quantification. Undocumented immigrants seeking to avoid detection are not likely to answer questions or participate in surveys they feel may reveal their immigration status and increase the risk for deportation [5]. The US Census Bureau, for example, only asks about citizenship status (either through birth or naturalization), but does not include questions about the immigration status of 
non-citizen respondents. While various methodologies have been proposed to provide estimates of undocumented immigrants, the most commonly accepted is the residual method [6]. Under the residual method, estimates of the foreign-born population (based on U.S. Census data) are compared with counts of immigrants considered to have their immigration documents in order (through naturalization, permanent residency status, or a current and valid visa) with the Department of Homeland Security (DHS). This comparison produces a residual that, after some adjustments for misreporting of naturalization, place of birth, emigration, and mortality, constitutes the count of undocumented immigrants [5] [6] [7] [8]. While some minor variations on the techniques for adjustments have been proposed [5], the residual methodology has not changed significantly since originally proposed and is considered to provide best available estimates of undocumented immigrant counts [7] [9].

While the residual method produces reliable counts of undocumented immigrants, it is limited in the type of information it provides about undocumented immigrants beyond counts, country of birth, age, gender, and other basic demographic characteristics that can be inferred from the census and DHS databases [7]. To overcome this limitation, other methods that use combinations of survey items that can identify a respondent's immigration status without directly asking for it have been proposed recently. Most notable, Passel and Clark use items in the Current Population Survey (CPS) in combination with Immigration and Naturalization Service (INS) data to identify (probabilistically) undocumented immigrants in the CPS sample [10]. Warren uses a similar method combining DHS data with items from the Census Bureau's American Community Survey (ACS) to identify (probabilistically) undocumented immigrants in that sample [7]. In addition, Pourat and colleagues proposed a method for identifying immigration status using items in the 2009 California Health Interview Survey (CHIS) to estimate access and utilization for undocumented immigrants in California [11].

In the present study, we build on Pourat and colleagues' methodology [11] using publicly available data from the 2011-12 CHIS to explore disparities in access to health care, coverage, and utilization by immigration status.

\section{Methods}

\subsection{Identification of Immigrant Status in the CHIS 2011-12 Survey}

We used the public use files of the CHIS for adult respondents (version 10.1). For its sample of 2011-12, the CHIS interviewed a representative sample of 42,935 Californian adults using a telephone survey employing a dual-frame (includes both cell and land-line phones) random-digit-dial technique [12]. The CHIS does not explicitly ask respondents about immigration status, but it does contain a set of questions including the respondent's country of birth, years in the US, citizenship status, among other demographic characteristics that we employed to construct an algorithm that identifies undocumented immigrants 
among respondents that were not born in the US.

Our proposed methodology used the following steps: using the CHIS sample for adults (18 years or older), we started with a subsample of respondents that identify as non-citizens that have been living in the US for more than 15 years. Following Passel's findings, we started with the premise that most immigrants that have been in the United States for more than 15 years and have not become US citizens (through naturalization) are most likely undocumented immigrants [13]. We then compared the two groups in the subsample (those that have gone through naturalization and those who are undocumented) based on income, age, education level, type of work, and country of origin, to estimate a predictive model using logistic regression. Finally, we used the predictive model to assign the likelihood of being undocumented for non-citizens living in the US for less than 15 years. Every non-citizen respondent assigned a probability of $60 \%$ or higher was classified as undocumented. At every classification point, we made adjustments based on whether the respondent indicated participation in programs only available to citizens or legal residents (e.g. Non-Maternal or emergency Medicaid or Medicare) or respondents who stated that they were denied services due to their immigration status.

\subsection{Estimates of Access and Utilization of Care}

After establishing immigration status, we made comparisons between immigration status groups and health care access. Our primary access to care question from the CHIS was "Is there a place that you usually go to when you are sick or need advice about your health?" In secondary analyses, we investigated relationships between immigration status and whether the respondents visited a doctor or the emergency room (ER) in the past year. Unadjusted odds were calculated for all predictors of access to care using generalized linear models. Multivariable models were built using the predictors that were significantly associated with access in the bivariate analyses. Adjusted odds ratios (aOR) and 95\% confidence intervals (CI) are reported. All analyses were performed in Stata 13.1 [14].

\section{Results}

\subsection{Immigrant Status Subgroups Identified}

Our algorithm applied to the 2011-12 CHIS sample of adults produced a population estimate of 2.03 million (M) (95\% CI 1.9 M - 2.2 M) undocumented adults living in California in 2011. This estimate is consistent with those of prior studies [11] [15] [16]. Overall, of the 42,935 respondents included in the CHIS sample of California adults, 31,801 (74.1\%) were self-reported US born citizens, 6735 (15.7\%) were naturalized citizens, 2232 (5.2\%) were legal permanent residents or visa-holders, and 2167 (5.0\%) were undocumented immigrants (see Table 1). The California population estimate for adults in each subgroup was 
Table 1. Characteristics of sample (\%).

\begin{tabular}{|c|c|c|c|c|c|c|}
\hline Characteristic & US Born & $\begin{array}{l}\text { Naturalized } \\
\text { Citizen }\end{array}$ & Permanent & Undocumented & Total & P Value \\
\hline Sample (N) & 31.801 & 6.735 & 2.232 & 2.167 & 42.935 & \\
\hline Population Estimate (M) & 18.44 & 4.98 & 2.35 & 2.03 & 27.8 & \\
\hline (ME) & $(0.3)$ & $(0.19)$ & $(0.15)$ & $(0.14)$ & & \\
\hline Gender & 49.0 & 45.3 & & & & \\
\hline Male & 51.0 & 54.7 & 49.2 & 54.2 & 48.7 & $<0.001$ \\
\hline Female & & & 50.8 & 45.8 & 51.3 & \\
\hline \multicolumn{7}{|l|}{ Age } \\
\hline $18-29$ & 27.8 & 10.8 & 26.1 & 12.8 & 23.5 & \\
\hline $30-49$ & 29.9 & 40.4 & 61.2 & 56.5 & 36.4 & \\
\hline $50-64$ & 24.3 & 31.2 & 10.9 & 22.6 & 24.3 & $<0.001$ \\
\hline 65 or older & 18.0 & 17.6 & 1.8 & 8.0 & 15.8 & \\
\hline \multicolumn{7}{|l|}{ Education (highest) } \\
\hline Less than High School & 6.7 & 23.6 & 38.3 & 55.8 & 16.0 & \\
\hline High School & 26.6 & 19.7 & 19.9 & 19.2 & 24.3 & $<0.001$ \\
\hline Some College/ & 21.2 & 12.4 & 11.5 & 9.9 & 18.0 & \\
\hline \multicolumn{7}{|l|}{ Vocational School } \\
\hline AA or AS & 8.4 & 5.8 & 1.6 & 2.9 & 7.0 & \\
\hline $\mathrm{BA}$ or $\mathrm{BS}$ & 22.5 & 23.8 & 17.7 & 8.4 & 21.3 & $<0.001$ \\
\hline Some Postgraduate Work+ & 22.5 & 23.8 & 11.0 & 3.9 & 13.5 & \\
\hline \multicolumn{7}{|l|}{ Race-Ethnicity } \\
\hline Hispanic & 23.3 & 41.1 & 63.8 & 82.9 & 34.2 & \\
\hline White (NH) & 59.1 & 16.8 & 9.0 & 7.0 & 43.5 & $<0001$ \\
\hline Asian $(\mathrm{NH})$ & 6.2 & 39.1 & 25.8 & 8.2 & 13.9 & $<0.001$ \\
\hline African American (NH) & 7.6 & 2.0 & 1.0 & 1.7 & 5.6 & \\
\hline \multicolumn{7}{|l|}{ American Indian/ } \\
\hline Alaskan Native (NH) & 0.6 & 0.1 & 0.0 & 0.0 & 0.4 & \\
\hline \multicolumn{7}{|l|}{ Native Hawaiian/ } \\
\hline Pacific Islander (NH) & 05 & 0.1 & 0.2 & 0.2 & 0.4 & \\
\hline Two or More NH Races & 2.7 & 0.7 & 0.3 & 0.2 & 2.0 & \\
\hline \multicolumn{7}{|l|}{ Employment-type } \\
\hline Unemployed & 38.4 & 36.3 & 34.4 & 29.2 & 37.0 & \\
\hline Private/Non-Profit & 38.6 & 43.4 & 54.2 & 55.3 & 41.8 & \\
\hline Government & 11.7 & 9.0 & 2.4 & 2.4 & 9.8 & $<0.001$ \\
\hline Self-Employment & 10.0 & 10.7 & 9.8 & 11.8 & 10.2 & \\
\hline Family Business/Farm & 1.3 & 0.7 & 1.0 & 1.3 & 1.2 & \\
\hline
\end{tabular}




\section{Continued}

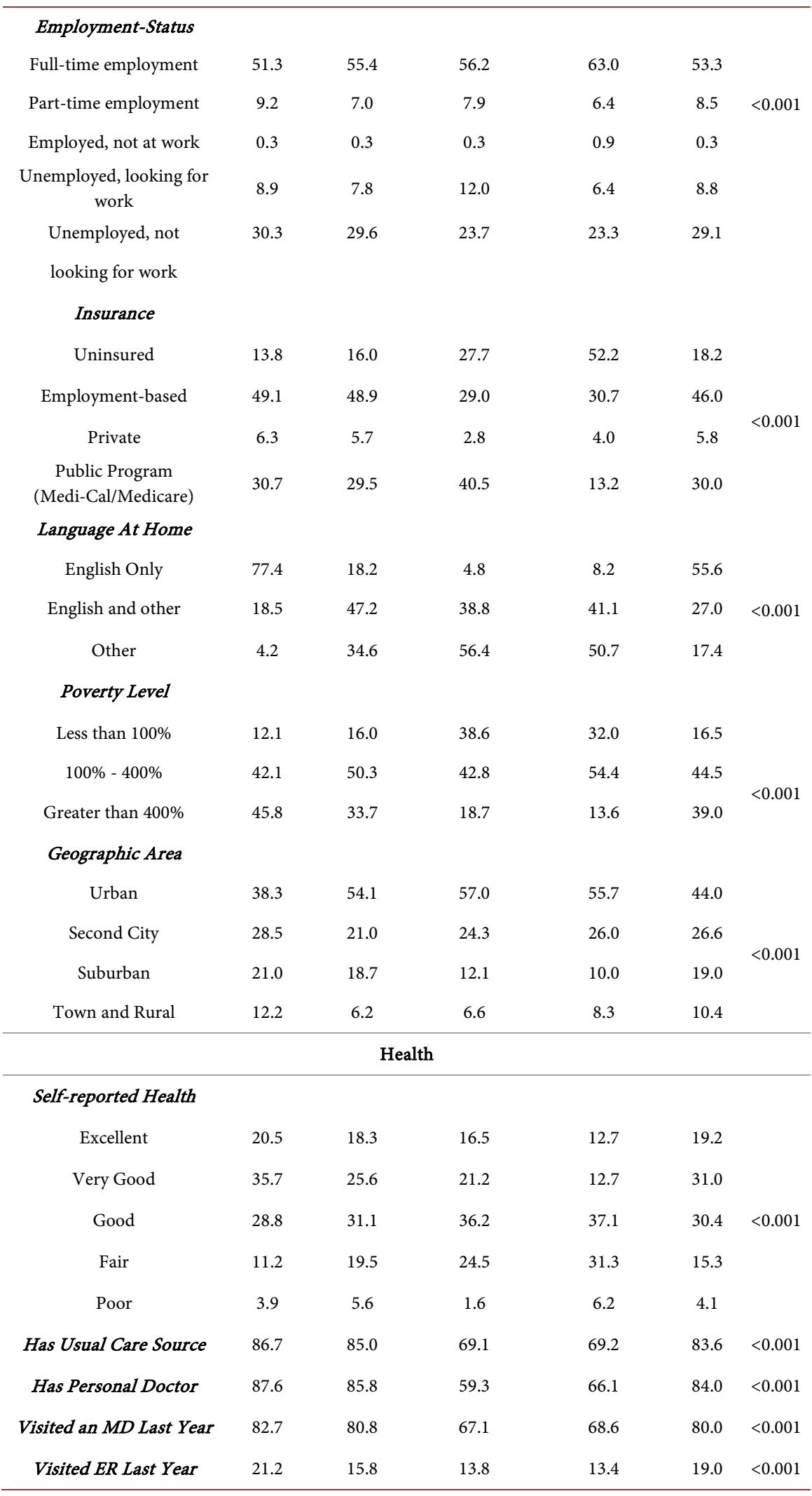

AA: Associate's in Arts; AS: Associate's in Science; BA: Bachelor's in Arts; BS: Bachelor's in Science; ER: Emergency Room; MD: Medical Doctor; ME: margin of error; NH: non-Hispanic. 
18.44 $\mathrm{M}$ (margin of error $(\mathrm{ME})=0.3)$ US born, 4.98M $(\mathrm{ME}=0.19)$ naturalized citizens, 2.35M $(\mathrm{ME}=0.15)$ permanent resident or visa-holders, and 2.03M $(\mathrm{ME}=$ 0.14 ) undocumented immigrants.

\subsection{Demographic Characteristics by Immigration Status}

As presented in Table 1, naturalized citizens were more often females $(54.7 \%)$, while undocumented immigrants were more often males (54.2\%). Both US born and permanent resident subgroups were equally male and female. Permanent residents were generally younger than the other immigrant status subgroups- $-87.3 \%$ were 18 - 49 years old, whereas approximately $51.2 \%-69.3 \%$ of the other subgroups were 18 - 49 years old. Three-quarters of the undocumented immigrants reported their highest level of education as high school or less, while a third (33.3\%) of US born reported their highest level of education as high school or less. More than $82 \%$ of undocumented immigrants were Hispanic, while Hispanics only made up about $23 \%$ of the US born citizens. Likewise, among US born, White, non-Hispanic citizens (59.1\%) were the most common race-ethnicity. Among undocumented immigrants, nearly two-thirds (63.0\%) were working full-time, the highest proportion among all immigrant status groups. In contrast, among US born, 30.3\% were unemployed and not looking for work, also the highest among all immigrant status groups. Over half (52.2\%) of all undocumented immigrants reported being uninsured, while $13.2 \%$ reported receiving insurance from a public program. Approximately $14 \%$ of US born are uninsured, while $16 \%$ and $28 \%$ of naturalized and permanent residents, respectively, reported being uninsured. Approximately $4 \%$ of US born reported speaking only a language other than English at home, while the majority of permanent residents and undocumented immigrants reported only a language other than English (56.4\% and 50.7\%, respectively). Approximately a third of the permanent residents and undocumented immigrants are living at less than $100 \%$ of the poverty line, while approximately $12 \%$ of US born and $16 \%$ of naturalized citizens are living at less than $100 \%$ of the poverty line. Lastly, there were no noted differences in declared geographic area of residence between naturalized citizens, permanent residents, and undocumented residents, though US born less commonly reported living in an urban environment and more commonly reported living in town/rural environments than all other subgroups.

\subsection{Self-Reported Health}

Approximately $56 \%$ of US born citizens reported their health as either excellent or very good. However, $44 \%$ of naturalized citizens, $38 \%$ of the permanent residents, and $25 \%$ of the undocumented immigrants reported their health as either excellent or very good.

\subsection{Usual Source of Care}

Our primary outcome of interest was whether the respondents had a usual source of care. Because insurance status is an effect modifier between immigration status 
and access to care, we stratified our results by whether the respondent had insurance. Among those respondents who were uninsured, US born citizens (aOR = 1.17; 95\% CI 0.86 - 1.60), naturalized citizens ( $\mathrm{aOR}=0.90$; 95\% CI 0.65 - 1.25), and permanent residents $(\mathrm{aOR}=0.99 ; 95 \% \mathrm{CI} 0.71-1.38)$ were not significantly more likely to report having a usual source of care than undocumented immigrants, after adjusting for known confounders (see Table 2). In contrast, among those respondents who were insured, permanent residents were significantly less likely than undocumented immigrants to report having a usual source of care $(\mathrm{aOR}=0.66 ; 95 \% \mathrm{CI} 0.46-0.95)$, after adjusting for known confounders.

\subsection{Secondary Analyses}

\section{Visited Doctor in Last Year}

In secondary analyses, we evaluated both visiting a doctor in the last year and visiting an ER in the last year, as they are both indicators of an individual's access to care (see Table 2). Among those respondents who were uninsured, US born citizens $(\mathrm{aOR}=1.05 ; 95 \%$ CI 0.76 - 1.45), naturalized citizens ( $\mathrm{aOR}=0.92$; 95\% CI 0.66 - 1.29), and permanent residents (aOR $=0.84$; 95\% CI $0.60-1.17$ ) were not significantly more or less likely to report visiting a doctor in the past year than undocumented immigrants, after adjusting for known confounders.

In contrast, among those respondents who were insured, US born and naturalized citizens were both significantly more likely to visit a doctor in the past year than undocumented immigrants, after adjusting for known confounders $(\mathrm{aOR}=$ 1.53; 95\% CI 1.15 - 2.04, aOR = 1.40; 95\% CI 1.05 - 1.87, respectively).

Table 2. Adjusted Odds Ratios ${ }^{\text {a }}$ Evaluating Relationships between Immigration Status and Access to and Utilization of Health Care (95\% CI)

\begin{tabular}{cccc}
\hline Immigration Status & $\begin{array}{c}\text { Usual Source of } \\
\text { Care }\end{array}$ & $\begin{array}{c}\text { Visited Doctor in } \\
\text { Last 12 Months }\end{array}$ & $\begin{array}{c}\text { Visited ER in Last } \\
12 \text { Months }\end{array}$ \\
\hline Undocumented & Reference & Refinsured \\
\hline US Born & 1.17 & 1.05 & Reference \\
& $(0.86-1.60)$ & $(0.76-1.45)$ & $(1.76-4.61)^{*}$ \\
Naturalized Citizen & 0.90 & 0.92 & 2.00 \\
Legal Permanent & $(0.65-1.25)$ & $(0.66-1.29)$ & $(1.16-3.46)^{*}$ \\
Resident & 0.99 & 0.84 & 1.08 \\
& $(0.71-1.38)$ & $(0.60-1.17)$ & $(0.60-1.93)$ \\
\hline Undocumented & & Insured & \\
\hline US Born & Reference & Reference & Reference \\
\hline Naturalized Citizen & 1.04 & 1.53 & 1.54 \\
Legal Permanent & $(0.72-1.51)$ & $(1.15-2.04)^{*}$ & $(1.15-2.06)^{*}$ \\
Resident & 1.06 & 1.40 & 1.15 \\
\hline
\end{tabular}

CI: confidence interval; ER: emergency room; a: All models adjusted for gender, age, education, income level, race-ethnicity, language spoken at home, rural/urban, and self-reported health status. ${ }^{*} \mathrm{p}$ value $<0.05$. 


\section{Visited ER in Last Year}

Among those respondents who were uninsured, US born citizens ( $\mathrm{aOR}=2.85$; 95\% CI 1.76 - 4.61) and naturalized citizens (aOR = 2.00; 95\% CI 1.16 - 3.46) were significantly more likely to report visiting the ER in the previous 12 months than undocumented immigrants, after adjusting for known confounders.

Similarly, among those respondents who were insured, US born citizens were significantly more likely to report visiting the ER in the previous 12 months than undocumented immigrants, after adjusting for known confounders $(\mathrm{aOR}=1.54$; $95 \%$ CI 1.15 - 2.06).

\section{Discussion}

The results presented in this paper provide the methodology by which future researchers could evaluate the impact of ACA within California, particularly in counties that provide services and coverage for the undocumented immigrant population. Our algorithm produced a population estimate of 2.03 undocumented adults living in California in 2011, which is similar to estimates from previous studies. Pourat and colleagues estimated a total of $2.2 \mathrm{M}$ undocumented immigrants (95\% CI 2.1 M - 2.43 M), including children for 2009 [11], and Passel and Cohn estimate 2.55M (95\% CI $2.35 \mathrm{M}-2.75 \mathrm{M})$, including children, for 2010 [9].

Our results highlight the role of insurance coverage for all immigrants regardless of immigration status. We found no evidence that a self-reported source of usual care for undocumented immigrants is more or less common than US born and naturalized citizens when controlling for insurance status. Furthermore, among those who are uninsured, we found no difference in annual doctor visits between immigrant subgroups. In contrast, we found that among those respondents who are insured, US born and naturalized citizens are significantly more likely to have a doctor visit in the previous 12 months when compared to undocumented immigrants ( $\mathrm{aOR}=1.53 ; 95 \% \mathrm{CI} 1.15,2.04$, aOR $=1.40 ; 95 \% \mathrm{CI} 1.05$ 1.87 , respectively). Additionally, US born are significantly more likely to use the ER in the previous 12 months than undocumented immigrants, independent of insurance status.

While overall health care utilization may be similar in the present study, our results, coupled with prior research [4] [17], have shown that undocumented immigrants have the lowest utilization rates of emergency departments, specifically, compared to other immigrants or US born citizens. A prior study using Medical Expenditure Panel Surveys from 2002 to 2011 also found that undocumented immigrants (6.7 visits in last 12 months) used the emergency department significantly less than legal residents (7.7 visits), naturalized citizens (10.4 visits), and US born (14.1 visits), while comprising a significantly greater proportion of uncompensated ER visits than US born citizens [17]. Although insured US born citizens are using ER significantly more often than undocumented immigrants, when considering only the uninsured, our results suggest 
that the probability of using the ER increases nearly two-fold among the US born relative to uninsured undocumented immigrants ( $\mathrm{aOR}=1.54$ for insured and $\mathrm{aOR}=2.85$ for uninsured).

Emergency Medicaid expenditures for undocumented immigrants is increasing, with the bulk of expenditures for childbirth and complications of pregnancy (82\%), though chronic diseases are also great contributors to these costs [18]. It should be noted, however, that Medicaid use is significantly less among undocumented immigrants than among documented immigrants [19]. Namely, Chung and colleagues found that undocumented immigrants were about half as likely as documented immigrants to receive Medicaid benefits ( $O R=0.48$; 95\% CI 0.33 - 0.69) [19]. Perhaps an expansion of care for undocumented immigrants for prenatal care would reduce complications and thus reduce emergency expenditures resulting from complications of pregnancy. Previous research suggests that childbirth-related hospitalizations are significantly higher among undocumented Latino immigrants than the general US population [20] [21]. The American College of Obstetricians and Gynecologists recognizes this disparity and has voiced its support for basic health care provisions for all women, regardless of immigration status [22]. Furthermore, not only would undocumented immigrants greatly benefit by being included in ACA coverage, but this would also be of great assistance to the hospitals with large, uncompensated health care costs resulting from uninsured, undocumented immigrants. These hospitals could potentially have increased revenues by receiving reimbursement for the care provided to those without health care insurance.

Lower health care expenditures among undocumented immigrants is likely not due to less needs from the population, but rather may be an artifact of undocumented immigrants not actively seeking medical care to avoid heavy out-of-pocket costs or perhaps as a result of mistrust of the health care system due to fears of discrimination and deportation, particularly for those immigrants who have pending immigration cases [2] [23] [24].

While undocumented and non-citizen immigrant groups are very similar in most demographic characteristics, they vary significantly on their type of coverage. Undocumented immigrants are more likely to lack insurance than comparable LPR immigrants. But among immigrants that have insurance, undocumented immigrants are more likely to report employment-based insurance, while LPRs are more likely to report enrollment in public insurance programs. The type of insurance may partly explain our finding that undocumented immigrants are more likely than comparable LPRs to report a usual source of care. This may have large implications on how the ACA will impact immigrants. While the ACA expansion of public programs may reduce the number of uninsured LPR immigrants, the employer mandate may also affect undocumented immigrants that rely heavily on employer-based coverage.

The present study has several limitations. First, the precision of our methodology for identifying undocumented immigrants using publicly available survey 
data relies on the accuracy of the assumption that most non-citizen respondents that do not seek naturalization after 15 years of residing in the United States can be considered undocumented. To the extent that this assumption is not accurate, our methodology may have misclassified legal residents as undocumented for this particular sub-group. Our algorithm classifies about $80 \%$ of migrants that have not opted for naturalization after 15 years of residence as undocumented. However, the overall counts and demographic characteristics we obtain from our methodology are comparable to previously published estimates that employed the Residual Method [15] [16]. Further when applied at the county level subsamples, our estimates are comparable to those that use Individual Tax Identification Numbers (ITIN) to estimate undocumented immigrants at that geographic level [25]. Second, our choice of dependent variable defined by the responses to "Is there a place that you usually go to when you are sick or need advice about your health?" may have impacted our results in an unknown direction. The interpretation of what constitutes a source of care could have potentially been disproportionately different between immigration status groups. The majority (52\%) of undocumented immigrants who reported a usual source of care identified community clinics as their primary source, while the majority (77\%) of US born who reported a usual source of care identified a family medicine doctor.

\section{Conclusions}

Our results suggest that undocumented immigrants in the US face important barriers to access health services that have important implications on their health. One of the main barriers is the lack of health insurance, mostly because most of them are not eligible for public programs available to US-born or documented immigrants. However, our results suggest that even with health insurance, undocumented immigrants are less likely to visit a doctor or use the emergency department than naturalized or US-born citizens. Undocumented immigrants may not actively, regularly seek care to avoid heavy out-of-pocket costs or perhaps have a mistrust of the health care system due to fears of discrimination and deportation.

Current political developments in the US have increased the fear of deportation and discrimination faced by undocumented immigrants. This state of fear is not only likely to have a direct impact on undocumented immigrants' health, but, as our findings suggest, it may also reduce the utilization of health services even further, just when they are needed the most.

\section{References}

[1] Capps, R. and Fix, M. (2013) Immigration Reform: A Long Road to Citizenship and Insurance Coverage. Health Affairs (Millwood), 32, 639-642.

https://doi.org/10.1377/hlthaff.2013.0187

[2] Raymond-Flesch, M., Siemons, R., Pourat, N., Jacobs, K. and Brindis, C.D. (2014) "There Is No Help Out There and If There Is, It's Really Hard to Find": A Qualitative Study of the Health Concerns and Health Care Access of Latino "DREAMers". 
Journal of Adolescent Health, 55, 323-328.

https://doi.org/10.1016/j.jadohealth.2014.05.012

[3] Sommers, B.D. (2013) Stuck between Health and Immigration Reform-Care for Undocumented Immigrants. The New England Journal of Medicine, 369, 593-595. https://doi.org/10.1056/NEJMp1306636

[4] Stimpson, J.P., Wilson, F.A. and Su, D. (2013) Unauthorized Immigrants Spend Less Than Other Immigrants and US Natives on Health Care. Health Affairs (Millwood), 32, 1313-1318. https://doi.org/10.1377/hlthaff.2013.0113

[5] Johnson, H.P. (1996) Undocumented Immigration to California, 1980-1993. Vol. 15. Public Policy Institute of CA. http://www.ppic.org/content/pubs/report/R_996HJR.pdf

[6] Passel, J.S. and Woodrow, K.A. (1984) Geographic Distribution of Undocumented Immigrants: Estimates of Undocumented Aliens Counted in the 1980 Census by State. The International Migration Review, 18, 642-671. https://doi.org/10.2307/2545891

[7] Warren, R. (2014) Democratizing Data about Unauthorized Residents in the United States: Estimates and Public-Use Data, 2010 to 2013. Journal on Migration and Human Security, 2, 305-328. https://doi.org/10.14240/jmhs.v2i4.38

[8] Warren, R. and Passel, J.S. (1987) A Count of the Uncountable: Estimates of Undocumented Aliens Counted in the 1980 United States Census. Demography, 24, 375-393. https://doi.org/10.2307/2061304

[9] Passel, J., Cohn, D. and Rohal, M. (2014) Unauthorized Immigrant Totals Rise in 7 States, Fall in 14: Decline in Those from Mexico fuels Most State Decreases. Pew Research Center, Washington DC. (Hispanic Trends Project)

[10] Passel J.S. and Clark R.L. (1998) Immigrants in New York: Their Legal Status, Incomes, and Taxes.

https://www.urban.org/research/publication/immigrants-new-york/view/full_report

[11] Pourat, N., Wallace, S.P., Hadler, M.W. and Ponce, N. (2014) Assessing Health Care Services Used by California's Undocumented Immigrant Population in 2010. Health Affairs (Millwood), 33, 840-847.

[12] California Health Interview Survey (2010) CHIS 2011-2012 Adult Questionnaire. Version 10.1. University of California, Los Angeles.

http://healthpolicy.ucla.edu/chis/design/Documents/CHIS2011adultquestionnaire.pdf

[13] Passel, J. and Center, P. (2007) Growing Share of Immigrants Choosing Naturalization. Pew Hisp Cent.

http://www.ecu.edu/cs-cas/anth/nuevosouth/upload/Latino-Naturalization-may-07. pdf

[14] StataCorp. 4905 Lakeway Drive, College Station, TX 77845.

[15] Passel, J.S. and D’Vera, C. (2011) Unauthorized Immigrant Population: National and State Trends, 2010.

http://www.pewhispanic.org/2011/02/01/unauthorized-immigrant-population-brna tional-and-state-trends-2010/

[16] Hoefer, M., Rytina, N. and Baker, B.C. (2011) Estimates of the Unauthorized Immigrant Population Residing in the United States: January 2011. Popul Estim off Immigr Stat Dep Homel Secur., 4.

[17] Stimpson, J., Wilson, F. and Zallman, L. (2014) Visits and Spending by Unauthorized Immigrants Compared with Legal Immigrants and US Natives. American Journal of Emergency Medicine, 32, 679. https://doi.org/10.1016/j.ajem.2014.03.018 
[18] DuBard, A. and Massing, M. (2007) Trends in Emergency Medicaid Expenditures for Recent and Undocumented Immigrants. JAMA, 297, 1085-1092. https://doi.org/10.1001/jama.297.10.1085

[19] Chung, Y. and Leigh, P. (2015) Medicaid Use by Documented and Undocumented Farm Workers. Journal of Occupational and Environmental Medicine, 57, 329-333. https://doi.org/10.1097/JOM.0000000000000357

[20] Berk, M.L., Schur, C.L., Chavez, L.R. and Frankel, M. (2000) Health Care Use among Undocumented Latino Immigrants. Health Affairs, 19, 51-64. https://doi.org/10.1377/hlthaff.19.4.51

[21] Reed, M.M., Westfall, J.M., Bublitz, C., Battaglia, C. and Fickenscher, A. (2005) Birth Outcomes in Colorado's Undocumented Immigrant Population. BMC Public Health, 5, 100. https://doi.org/10.1186/1471-2458-5-100

[22] Committee on Health Care for Underserved Women (2015) Health Care for Unauthorized Immigrants. Committee Opinion No. 627: Health Care for Unauthorized Immigrants. Obstetrics \& Gynecology, 125, 755-759. https://doi.org/10.1097/01.AOG.0000461771.63747.37

[23] Amuedo-Dorantes, C., Puttitanun, T. and Martinez-Donate, A.P. (2013) How Do Tougher Immigration Measures Affect Unauthorized Immigrants? Demography, 50, 1067-1091. https://doi.org/10.1007/s13524-013-0200-x

[24] Chavez, L.R. (2012) Undocumented Immigrants and Their Use of Medical Services in Orange County, California. Social Science \& Medicine, 74, 887-893. https://doi.org/10.1016/j.socscimed.2011.05.023

[25] Hill, L.E. and Johnson, H.P. (2011) Unauthorized Immigrants in California: Estimates for Counties. Public Policy Institute of CA.

http://www.ppic.org/publication/unauthorized-immigrants-in-california-estimatesfor-counties/ 